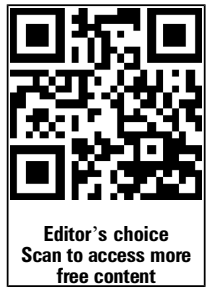

Department of Paediatrics, Broomfield Hospital, Chelmsford, UK

\section{Correspondence to}

Dr J Cyriac Department of Paediatrics, Broomfield Hospital, Chelmsford, CM1 7ET, UK; Job.Cyriac@meht.nhs.uk

Received 10 June 2013 Revised 13 March 2014 Accepted 2 June 2014 Published Online First 17 July 2014

\title{
Whistles and wheezes: don't miss diseases
}

\author{
J Cyriac, K Huxstep
}

\begin{abstract}
Upper airway obstruction (UAO) in infants and children has a broad spectrum of presentations including benign self-resolving conditions, from mild croup, to critical life-threatening conditions which, though uncommon now, require prompt recognition and effective multidisciplinary collaborative management to achieve a good outcome. The aim of this article is to highlight the diagnostic and management difficulties in acute UAO in paediatric patients and encourage a problem-solving approach.
\end{abstract}

\section{INTRODUCTION}

You are a senior paediatrician working in a busy district general hospital (DGH). Your team consists of second-year house officers, general practice trainees and junior paediatric specialist trainees. You all cover neonates, the paediatric ward and the emergency department (ED). Your ward is busy with paediatric medical patients and children under the orthopaedics, Ear Nose and Throat (ENT) specialists, plastic and general surgery teams. Your colleagues in anaesthesia, ENT, surgery and other specialities are all able to deal with paediatric patients, but can be less than enthusiastic. Today you are on call and taking over from a colleague.

\section{SAM}

Eleven-month-old infant Sam was admitted to the ward the day before through the ED. A previously fit and well child, he had been left unattended briefly the day before while in the care of a babysitter. When the babysitter returned to the room he had a blunt pencil in his mouth. The pencil was removed and appeared intact. No external injury was seen. However, a few hours later Sam developed sudden onset breathing difficulties, and was taken by his parents to the ED.

Sam was seen promptly by the ED medical staff who noted noisy breathing and mild dribbling. He was afebrile but unsettled with a respiratory rate (RR) of 32 , heart rate (HR) of 160 and oxygen saturation $(\mathrm{SaO} 2)$ of $99 \%$ in air. His chest was clear and there was no injury seen in the mouth. An acute UAO was suspected. Potential differential diagnoses of acute stridor were considered: see table 1.

Chest X-ray and lateral neck X-rays did not show any radio-opaque foreign bodies; figures 1 and 2 .

Sam was seen quickly by the paediatric team by which time his breathing had become more stridulous and there was more drooling and respiratory distress.

Table 1 Differential diagnoses of acute stridor

\begin{tabular}{|c|c|}
\hline Potential diagnosis & Signs and symptoms \\
\hline $\begin{array}{l}\text { Acute } \\
\text { laryngotracheobronchitis }\end{array}$ & $\begin{array}{l}\text { Prodromal symptoms: runny nose, mild fever, hoarse voice, barking cough followed } \\
\text { by inspiratory stridor }\end{array}$ \\
\hline Acute epiglottitis & High fever, toxic, drooling, extended neck \\
\hline Bacterial tracheitis & Fever, toxic, productive chesty cough, recent history of croup \\
\hline Inhaled foreign body (FB) & $\begin{array}{l}\text { Sudden onset of wheeze and/or stridor, unilateral chest findings, FB seen on } \\
\text { radiograph, overinflation of one lobe on X-ray }\end{array}$ \\
\hline Angioneurotic oedema & History of exposure to allergen, swelling of face, lips, eyes, etc. Wheeze, rash \\
\hline Diphtheria & $\begin{array}{l}\text { Uncommon, incomplete immunisation history, coryzal, sore throat, pseudomembrane } \\
\text { seen in the throat }\end{array}$ \\
\hline
\end{tabular}

To cite: Cyriac J, Huxstep K. Arch Dis Child Educ Pract Ed 2015:100:132-143. 
His HR was 168; saturations were $100 \%$ now on $15 \mathrm{~L}$ facial oxygen, with a RR of 45 . He remained afebrile. Sam had nasal flare, intercostal recessions and grunting, with desaturations to $80 \%$ when agitated. A mild generalised swelling of the neck was also noted. ENT and anaesthetic reviews were promptly requested.

A capillary blood gas did not show any carbon dioxide $\left(\mathrm{CO}_{2}\right)$ retention or acidosis. The ENT team reviewed him and confirmed no signs of injury in the mouth or throat. Chest X-ray and neck radiograph were reviewed by the ENT team, and confirmed the absence of any radio-opaque foreign bodies. They recommended supplemental oxygen, intravenous antibiotics, and intravenous dexamethasone and continued monitoring. The anaesthetic team were reassured that he was adequately maintaining his airway with a normal gas exchange. He was admitted to the ward for further observation and monitoring.

Sam spiked a temperature to $38.9^{\circ} \mathrm{C}$ in the early evening and he started grunting with a tachycardia of 190 and a RR of 40. Repeat blood gas was normal. He was seen by the paediatric consultant overnight who found him to be drowsy and noted significant wheeze with prolonged expiratory phase. Along with nebulised salbutamol and adrenaline, intravenous salbutamol was initiated. At this stage, the impression was of severe viral induced wheeze. A further blood gas was done which was acceptable, and the anaesthetic team felt that his respiratory symptoms were slightly better. Overnight, Sam remained tachycardic; this was felt to be secondary to salbutamol.

You are on the morning ward round. You review the history, examination findings and the investigations from the notes. He is quite unsettled and the clinical examination is very limited. The most you find on examination is stridulous breathing, generalised erythema on a mildly swollen neck, a normal throat examination, some recession, a lot of transmitted sounds on chest auscultation and a very unhappy child!

You go through the notes once again. You reconsider the differential diagnoses of acute airway obstruction and responses to each modality of treatment: see table 2 .

What could be the aetiology of this UAO?

Back to square one. You take the history from parents once again. This was a completely well child with no prodromal symptoms who was left with the childminder for a couple of hours while the parents went shopping. The childminder did tell the parents about the retrieval of the pencil from the child's mouth and the pencil was intact. There was no history of any crying or distress at this stage. When Sam was picked up from the childminder he was sleeping in the car seat. According to the parents, in the middle of the journey home, he woke up, started crying suddenly, and developed respiratory distress. The story doesn't quite fit. Healthy children do not wake up from a comfortable sleep with a severe respiratory

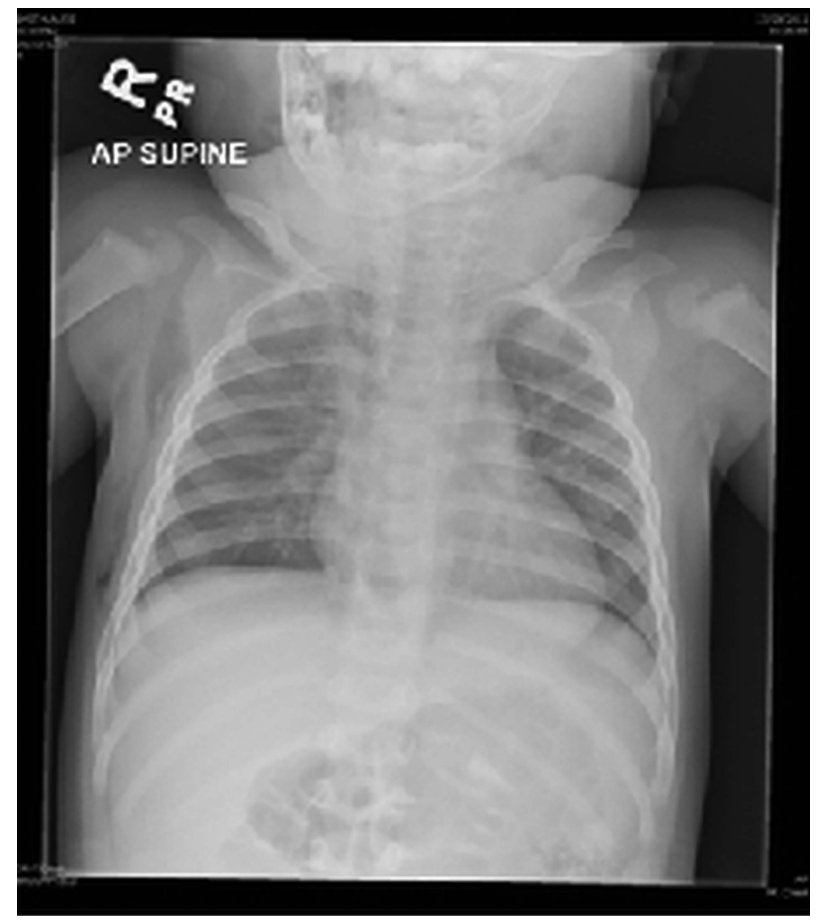

Figure 1 Chest radiograph.

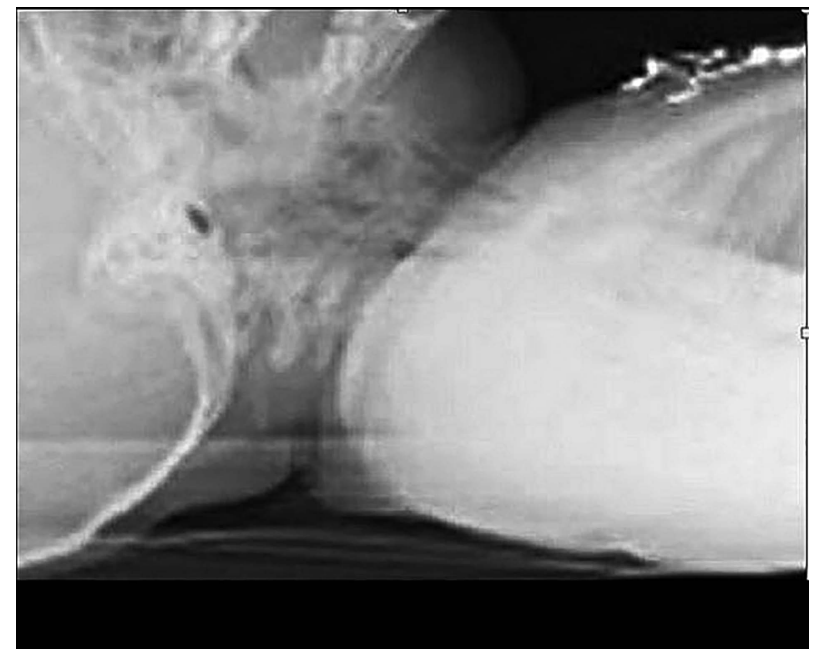

Figure 2 Lateral neck radiograph.

distress! A piece of the jigsaw is missing. You take the history once again. The story is consistent. Are the parents withholding any history? Is the babysitter withholding any history? Sam is still upset and uncooperative, hence no further clues from examination.

You look at the nursing charts and investigations again. Apart from an increased RR and HR, he had a couple of temperature spikes-albeit low grade. The C-reactive protein (CRP) has increased from 10.5 to $63 \mathrm{mg} / \mathrm{dL}$ and white cell count is normal. You review the chest X-ray. Wait a minute, is there air in the lateral chest wall? See figure 3. You review the upper airway silhouette in the lateral neck X-ray. This does not look normal! You cannot delineate the normal airway pattern. You review some normal library 
Table 2 Potential differential diagnoses and management of acute airway obstruction

\begin{tabular}{|c|c|c|}
\hline Differential diagnosis & Evidence for & Evidence against \\
\hline Foreign body aspiration & $\begin{array}{l}\text { History of retrieval } \\
\text { of pencil. Sudden } \\
\text { onset, no } \\
\text { prodromal } \\
\text { symptoms }\end{array}$ & $\begin{array}{l}\text { No evidence of } F B \text { on } \\
\text { the radiograph }\end{array}$ \\
\hline Traumatic injury & $\begin{array}{l}\text { History of playing } \\
\text { with a sharp object }\end{array}$ & $\begin{array}{l}\text { No evidence of injury } \\
\text { on ENT examination }\end{array}$ \\
\hline $\begin{array}{l}\text { Acute } \\
\text { laryngotracheobronchitis }\end{array}$ & $\begin{array}{l}\text { Stridulous } \\
\text { breathing, } \\
\text { non-toxic, common } \\
\text { diagnosis }\end{array}$ & $\begin{array}{l}\text { No response to steroids } \\
\text { or adrenaline nebulisers }\end{array}$ \\
\hline Acute epiglottis & $\begin{array}{l}\text { Fever albeit low } \\
\text { grade, stridulous } \\
\text { breathing, drooling }\end{array}$ & $\begin{array}{l}\text { No prodromal } \\
\text { symptoms, fever spike } \\
\text { only after admission, no } \\
\text { improvement to } \\
\text { intravenous antibiotics }\end{array}$ \\
\hline Acute asthma & $\begin{array}{l}\text { Generalised } \\
\text { wheeze, common } \\
\text { diagnosis }\end{array}$ & $\begin{array}{l}\text { Only transient } \\
\text { improvement to } \\
\text { maximum } \\
\text { bronchodilators and } \\
\text { steroids }\end{array}$ \\
\hline
\end{tabular}

ENT, ear, nose and throat; FB, foreign body.

images and compare, see figures 4 and 5 . The normal lateral airway silhouette is completely disrupted.

There is extensive surgical emphysema in the neck and chest. Sam is re-examined and you elicit palpable crepitus in the chest wall. You discuss your thoughts with the on-call radiologist, who confirms surgical emphysema. With the findings of erythematous neck swelling and surgical emphysema clinically and radiologically, a conclusion of traumatic upper airway compression is made.

\section{Comment}

Surgical emphysema is usually a self-limiting condition, but involvement of the hypopharynx may cause airway obstruction. An acute rise in intra-alveolar pressure can cause air to dissect soft tissue causing compression. ${ }^{1}$ Dissection of air into the soft tissues of the neck causes sore throat, dysphagia and dysphonia which sometimes mimic the symptoms of epiglottitis. ${ }^{1}$ Several cases of surgical/subcutaneous emphysema causing airway compromise are described in the literature. ${ }^{1-3}$

The ball starts to roll from here, or does it? Your anaesthetic colleague reviews Sam promptly and is keen to intubate and stabilise him. The case is discussed with the transport team who are reluctant to retrieve Sam as he is still maintaining his own airway and his gas exchange is acceptable. You have a lengthy three way conference call with the retrieval consultant and anaesthetic consultant, and finally, the transport team finds a paediatric intensive care bed and agrees to transfer Sam. He is transferred to theatre for intubation and stabilisation in the presence of the ENT team. Rapid-sequence induction is done in the theatre and a microlaryngoscopy performed. The

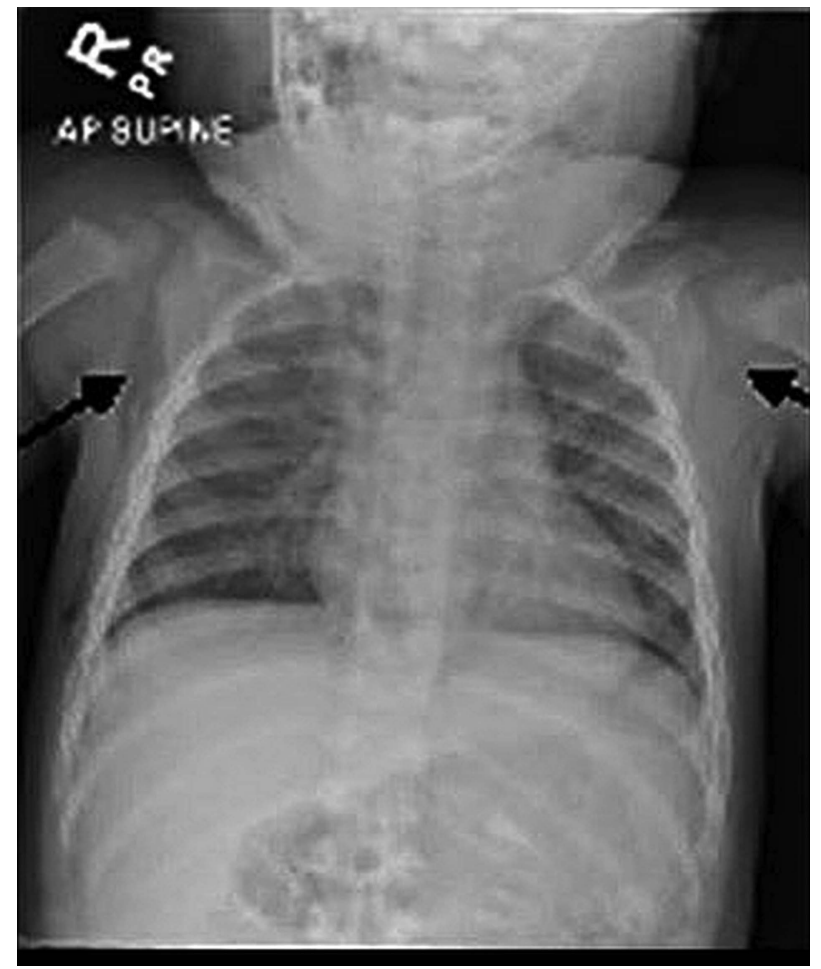

Figure 3 Subcutaneous emphysema.

oropharynx, supraglottis and glottis are found to be normal. Sam is transferred to the tertiary centre with suspected lower airway trauma.

At the tertiary centre, gastroscopy confirms an oesophageal tear and oesophagogram demonstrates a leak of contrast from the lower oropharynx into the mediastinum and right pleural space, see figure 6 . While in the intensive care, Sam develops right upper lobe collapse and pneumomediastinum. CT chest shows surgical emphysema and bilateral pleural

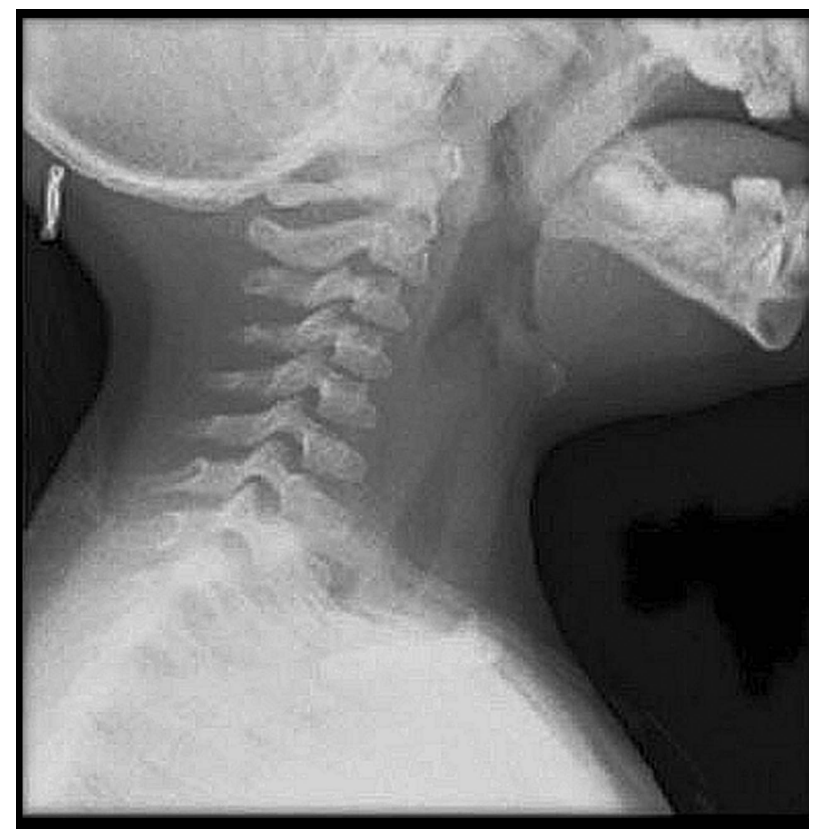

Figure 4 Normal lateral airway. 


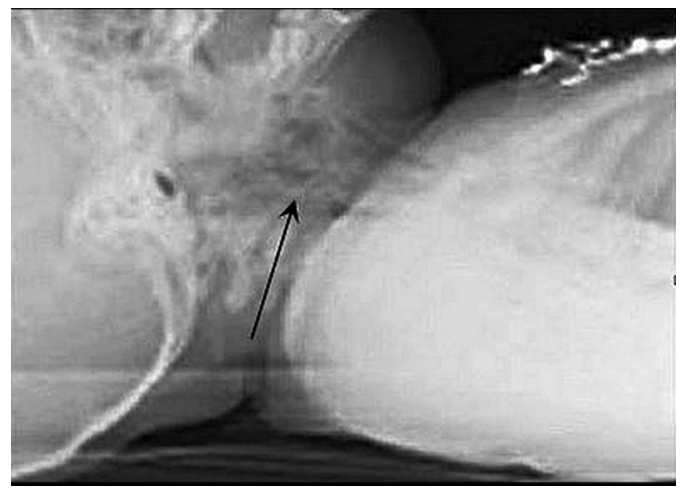

Figure 5 Disrupted lateral airway.

effusions which are drained. The pharyngeal penetrative injury is managed conservatively with nil by mouth for 6 weeks and gastrostomy feeding. When feeds are restarted, a diverticulum develops at the perforation site which needs resection. This diverticulum is demonstrated in figure 7. Fourteen months after the injury, Sam is feeding orally with no current complications, but he remains under regular follow-up.

A conclusion of traumatic perforation of the lower oropharynx caused by a pencil was declared at a multidisciplinary safeguarding meeting.

\section{Comment}

Foreign body injury from aspiration or ingestion is a common problem in paediatrics. It has been shown that only $85 \%$ diagnoses are made on the first encounter. ${ }^{4}$ Delays of diagnosis are seven times more likely with aspirations than ingestions. ${ }^{4}$ Secondary complications, such as pneumonia or atelectasis occur in $13 \%$ of airway foreign bodies, but only $1.7 \%$ of oesophageal foreign bodies. Oesophageal foreign bodies require early intervention as they have the

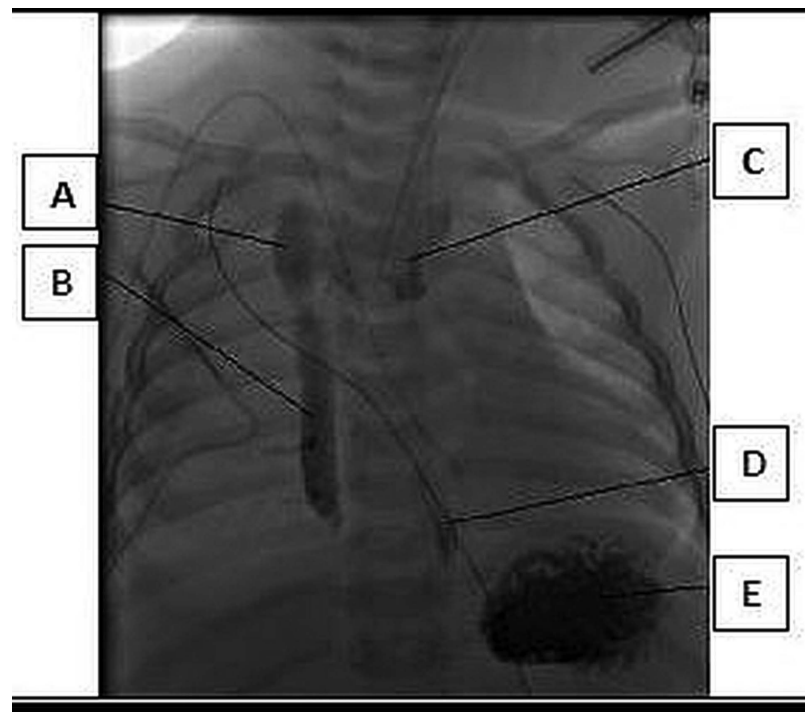

Figure 6 Oesophagogram. (A) Leak into right pleural space. (B) Further leak into mediastinum. (C) Oesophagus. (D) Distal oesophagus. (E) Stomach.

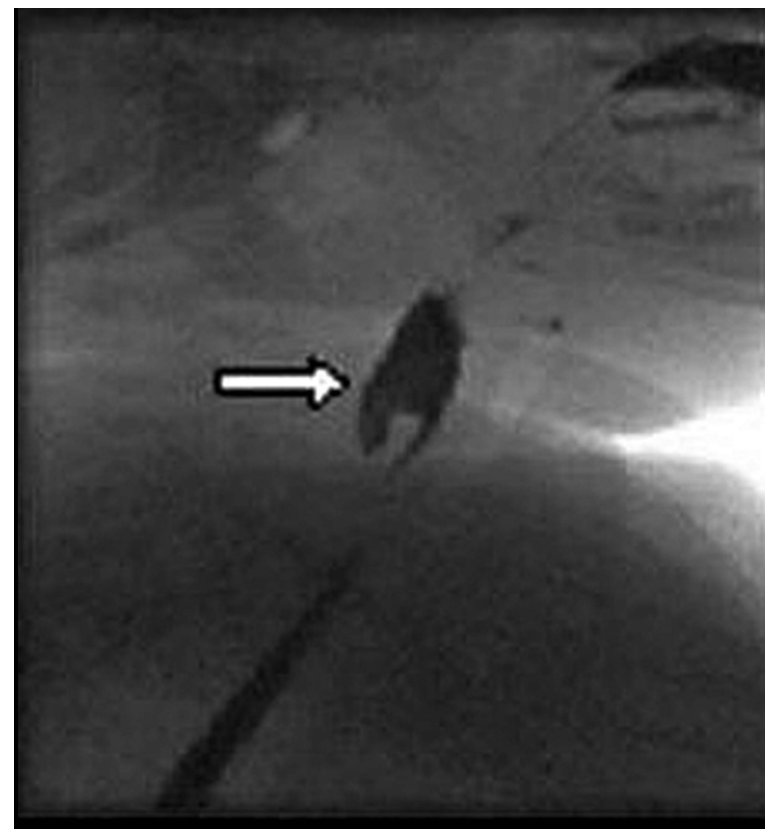

Figure 7 Oesophageal diverticulum.

potential to cause respiratory symptoms, erosions and even aorta-oesophageal fistulae. ${ }^{5}$ Sharp foreign bodies can increase the complications from $<1 \%$ to $15 \% .^{5}$

\section{SOPHIE}

20-month old Sophie presented to the paediatric ward with a 6-week history of being snuffly and snotty. She had seen the GP 3 weeks previously with increasing yellow secretions from the nose and mouth and was treated with amoxicillin. One week later, she was seen by the paediatric team with reduced fluid intake. Sophie was afebrile, HR was 168 and RR was 28 with

\section{Learning points}

The foreign body history was known from the outset -absence of foreign body on investigation does not exclude an injury caused by foreign body.

- Sam was eating but not drinking - usually it is the other way round.

- Unexplained tachycardia should always be monitored carefully.

- When ordering tests, remember to look at everything. The chest $\mathrm{X}$-ray was clear for radio-opaque foreign bodies, but held the clues for diagnosis of surgical emphysema.

- Non-accidental injuries should be high in the list of differential diagnoses, particularly with atypical presentations.

- Review the case from the beginning and make up your own mind. Think inside and outside the box. There was suggestion in the history to suspect complication from foreign body injury.

- Review radiological investigations systematically (see box 1) 
normal saturations. She was irritable on examination and had moderate cervical lymphadenopathy, thick secretions from her nose and mouth and enlarged tonsils. A chest X-ray was done to exclude lower respiratory tract infection, and she was discharged home with suspected viral upper respiratory tract infection (URTI). Prior to this illness, Sophie had no history of any significant medical illness.

Sophie was re-admitted 2 weeks later with no improvement. She was tachycardic, but her RR and saturations were normal, and she was again afebrile. On examination Sophie had conducted sounds to the chest and noisy breathing of upper airway in origin. She was thought to have allergic rhinitis and a provisional plan was made to discharge home with nasal drops and to come back for the morning ward round. However, Sophie failed to drink enough or improve with antihistamines, so was admitted overnight. Blood tests revealed a mildly raised white cell count at $16 \times$ $10^{9} / \mathrm{L}$ and CRP was $2.8 \mathrm{mg} / \mathrm{dL}$.

Box 1 A systematic approach to evaluating chest radiographs $^{6}$

Check patient's name, date of birth and hospital number Date of examination and side marking

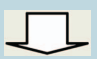

Check projection, phase of respiration, rotation, artefact

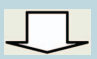

Trachea, main bronchi and hilar regions

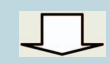

Superior mediastinum—size and shape

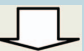

Heart and great vessels—cardiac shadow $<60 \%$

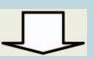

Lungs, pleural cavities and patterns of disease: Increased translucency, air leaks, increased opacification, pulmonary nodules, ring shadows

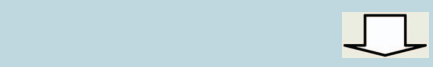

Diaphragms

Thoracic skeleton and soft tissues

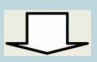

Other areas: behind the clavicles, mediastinum, retrocardiac regions of lung bases
In the early evening, the senior paediatric trainee on-call contacted the ENT team as he was concerned that Sophie would only sit with her neck extended in the 'sniffing the morning air' position (box 2). The ENT junior doctor found noisy breathing, yellow secretions in the nose and throat and felt that rhinitis, laryngitis or pharyngitis was likely and decided to treat with Co-amoxiclav and saline nasal drops. He thought that Sophie could wait till the next day for further ENT input.

The paediatric and ENT consultants saw Sophie the next day. She was stertorous, with noisy secretions and sitting in the neck extended position. Sophie had cervical lymphadenopathy and very large tonsils which were almost touching. Her voice was normal. Glandular fever causing enlargement of tonsils was suspected. Blood film and Monospot tests were requested and Sophie was started on steroids.

\section{Comment}

Airway compromise due to swelling of pharyngeal tissues can result from many infectious and noninfectious processes. ${ }^{8}$ Enlargement of tonsillar and nasopharyngeal lymph nodes is common in glandular fever; this is due to inflammation of the lymphoid tissue in Waldeyer's ring. ${ }^{8}$ Cases causing respiratory obstruction requiring tracheostomy have been reported. ${ }^{9}$ Obstruction can also be attributed to oedema of the glottis or occlusion of the trachea. Corticosteroids are thought to have a role in hastening resolution of the symptoms. ${ }^{10}$ Steroids are generally used for more severe airway symptoms. A Cochrane

\section{Box 2 Sniffing the morning air neck position}

Ivan Magill described the positioning of the head for intubation as

'sniffing the morning air'

'draining a pint of beer'

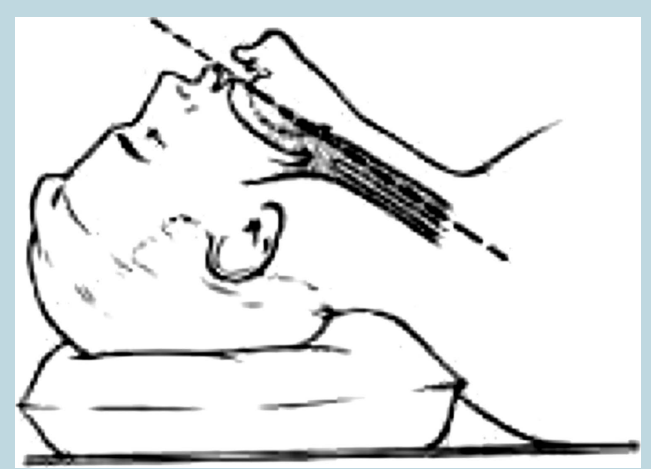

Describes how the neck is flexed forward to $35^{\circ}$ using one pillow under the head. The head is then extended on the neck so that the face is tilted back $15^{\circ}$ from the horizontal $^{7}$ 
review in 2009 showed insufficient evidence for steroid use in routine symptom control. ${ }^{11}$

The Monospot test was negative and blood film did not show any reactive lymphocytes.

You take over the next morning. You review the history, investigations performed and input from the colleagues. On examination you note that Sophie continues to be unwell. Throat examination is difficult; it seems there is a crowding of posterior oral structures. There is also a soft swelling on the left submandibular region and marked neck extension. Could this be to maintain her airway? Is there a mechanical cause? You contact the ENT consultant yourself. They suggest an ultrasound of the neck to review the soft tissues, but suggest this can wait until the next day. You insist on a consultant review. Sophie is reviewed, and they confirm stertor and multiple small, non-tender, nonfluctuant cervical nodes. A soft tissue lateral neck $\mathrm{X}$-ray is requested. The lateral neck X-ray (figure 8), shows increased prevertebral soft tissue shadowing, very suspicious of retropharyngeal abscess (RA). Evaluation of RA and retropharyngeal space (RS) on a lateral neck radiograph is described in boxes 3 and 4 .

Sophie is discussed with a tertiary ENT centre who suggests more intravenous antibiotics, a CT scan of neck, and to contact them the next day. At 03:00, Sophie has an apnoea; initially self-terminating, but they become recurrent. ENT trainee reviews again and thinks she is tiring, but as she currently can maintain her airway, they decide to rediscuss with the tertiary centre in the morning. Sophie copes for the next $4 \mathrm{~h}$ in a sitting position. In the morning, arrangements are made to transfer Sophie to the tertiary centre. The transport team requests that she is intubated and stabilised before transfer. Sophie is moved to the theatre and three consultant anaesthetists struggle to insert an endotracheal tube. Finally the ENT consultant, with the help of a rigid bronchoscope, manages to insert a bougie then guide the endotracheal tube over it.

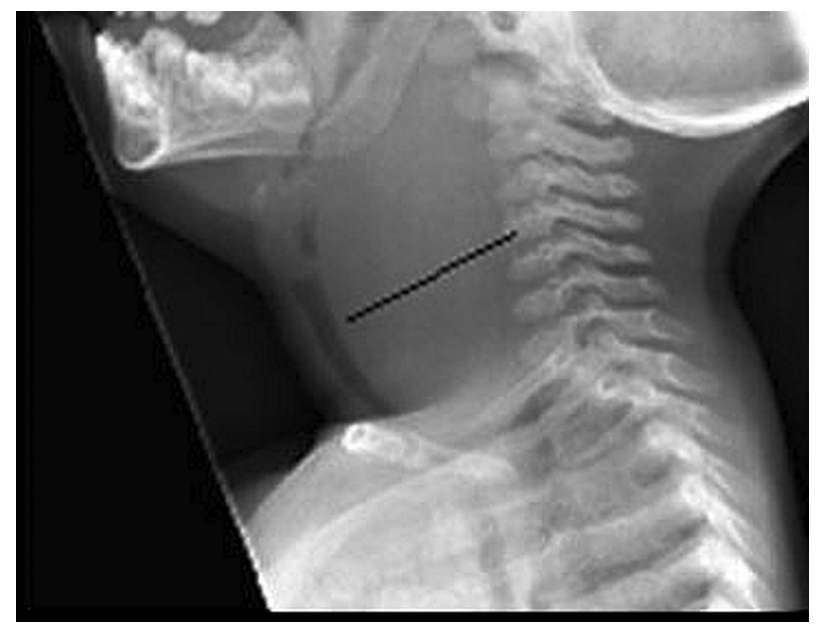

Figure 8 Increased prevertebral space.
Sophie is admitted to intensive care for incision and drainage. Copious amount of pus positive for $\alpha$-haemolytic Streptococcus and anaerobes is drained from the retropharyngeal abscess. Sophie recovers well with no further complications.

\section{Learning points}

Beware reattenders and non-responders. Don't be afraid to rethink the diagnosis.

- Other specialities may be less confident with paediatrics-don't be afraid to push for senior review, not everything should wait until the morning!

- This child remained afebrile and the CRP was low. But these cannot exclude a localised abscess, particularly when the child has been given repeated courses of antibiotics previously.

- Consider carefully repeated throat examinations in a child with potential upper airway compromise.

- Stertor versus stridor-get it right (see table 3)

- Ensure experienced people are around for intubating these children.

- Beware the tachycardic child!

\section{PETER}

Peter was born prematurely at 33 weeks gestation with a weight of $2.2 \mathrm{~kg}$ to a primiparous mother. At birth he needed airway positioning and inflation breaths to initiate respiration. Peter breathed spontaneously for the first few minutes, but needed more inflation breaths after a brief drop in saturations and poor respiratory effort. After 5 min he was stable and transferred to the neonatal intensive care unit (NICU), but at $12 \mathrm{~h}$ of age he had a sustained apnoea which briefly required resuscitation. He continued to have apnoeas and episodes of profound desaturations, which mostly responded to airway positioning and bag and mask ventilation. Micrognathia was noted in addition to a possible small cleft palate.

Pierre Robin Sequence (PRS), box 5, was taken into consideration; hence a nasopharyngeal airway (NPA) was inserted.

However, insertion of the NPA did not result in resolution of the apnoeas and desaturations with $\mathrm{CO}_{2}$ rising to $9 \mathrm{kPa}$. Peter was also noted to have an intermittent biphasic stridor, and he was commenced on continuous positive airway pressure (CPAP) which did make a significant improvement to the symptoms, and the $\mathrm{CO}_{2}$ reduced to $6.9 \mathrm{kPa}$. Meanwhile, the plastic surgery team ruled out cleft palate and did not feel that the child had the full PRS.

In addition to the micrognathia, Peter had other dysmorphic features including low-set ears, hypertelorism, small rounded scrotum, and flexed big toes. An echocardiogram was done in view of a significant 


\section{Box 3 Retropharyngeal abscess}

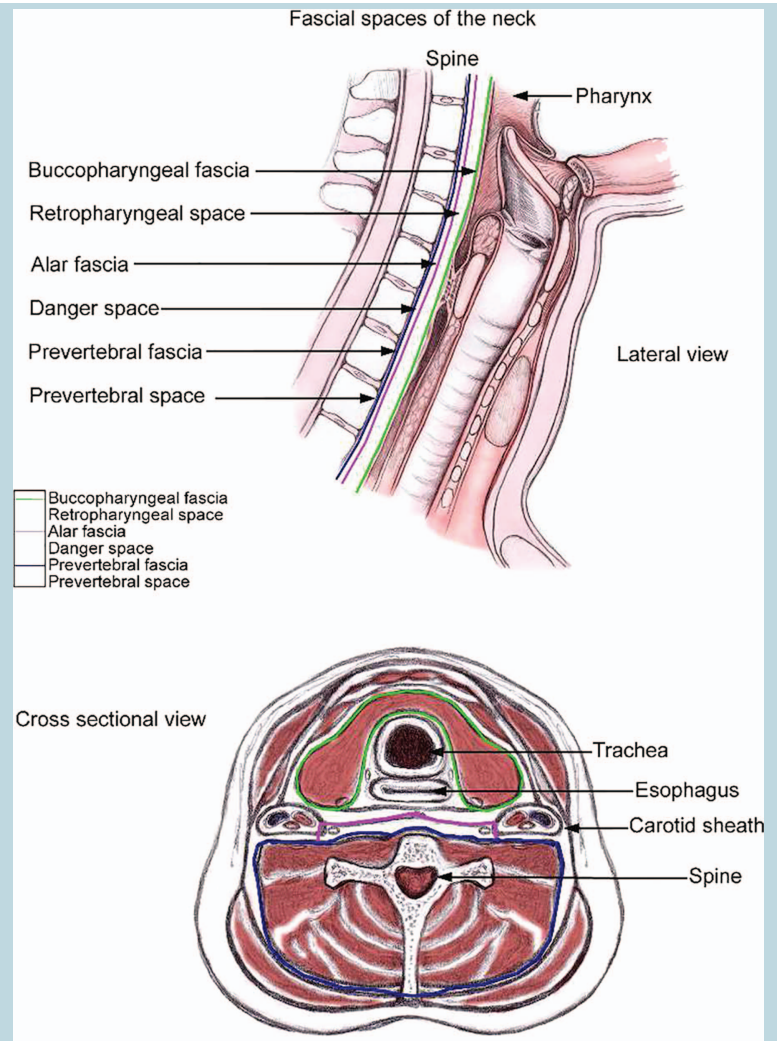

(Image reprinted with permission from Medscape ${ }^{12}$ )

- The retropharyngeal space is immediately posterior to the pharynx, larynx and trachea.

- Visceral fascia which surrounds the pharynx, trachea, oesophagus and thyroid forms the anterior border. The posterior border is the alar fascia, and laterally is the carotid sheath and parapharyngeal spaces.

- Other anatomical relationships mean infection can spread into the mediastinum.

- Abscess is usually secondary to lymphatic spread of ear nose and throat (ENT) infections.

- Causative organisms are mainly Streptococcus pyogenes and Staphylococcus aureus.

- Presentation, initially, can be vague with upper respiratory tract infection, neck stiffness, fever, sore throat, limitation of neck movement, etc. ${ }^{13}$

- Progresses to show extrathoracic airway compromise -drooling, stridor, respiratory distress. ${ }^{14}$

- Retropharyngeal mass may be seen on external neck examination.

- Forceful examination of neck is discouraged. ${ }^{14}$

- Lateral neck X-ray in full extension shows increased thickness of the prevertebral space.

- Most centres recommend a trial of antibiotics before surgery-resolves in $25 \% .{ }^{15}$

- The airway should be protected by careful intubation before surgical drainage.
- CT scan with contrast is the investigation of choice.

Box 4 Lateral neck radiograph evaluation of retropharyngeal space ${ }^{16}$

Space between posterior pharyngeal wall and anterior body of the vertebrae.

- Normally thicker in children-usually less than the size of one vertebral body, but can expand to the width of three when crying with the neck flexed, or in forceful expiration.

- As a general rule, considered abnormal if the width of the retropharyngeal space (RS) at the level of the second vertebra is twice the antero-posterior (AP) diameter of the second vertebrae.

- Loss of cervical spine lordosis in retropharyngeal abscess (RA).

- RS may show gas or fluid levels.

- RS measurements can be affected by posture, respiratory motion, crying, swallowing etc.

systolic murmur and a moderate ventricular septal defect (VSD) was found. The lungs appeared normal on chest X-ray, but his thymus was thought to be absent. Routine bloods also revealed hypocalcaemia. In view of these findings Peter was suspected to have DiGeorge Syndrome and, in addition to sending bloods for 22q11.2, a genetic review was requested. Peter was later confirmed to have DiGeorge Syndrome (see box 6 for salient features).

On day 7, Peter had an unsuccessful trial to come off CPAP and an ENT review was requested. The local ENT team did a flexible nasal endoscopy which showed erythematous arytaenoids folds; no cause was found for the UAO but they did not visualise past the vocal cords. Erythematous arytaenoids folds suggested gastro-oesophageal reflux and he was started on reflux medications. Additionally, an urgent faxed

Table 3 Stertor versus stridor

\begin{tabular}{lll}
\hline & Stertor & Stridor \\
\hline Cause/ & Generated from & Turbulent air flow through \\
location & nasopharynx, oropharynx & $\begin{array}{l}\text { partially obstructed } \\
\text { supraglottis, glottis, } \\
\text { and occasionally supraglottis } \\
\end{array}$ \\
& subglottis and/or trachea
\end{tabular}

\begin{tabular}{|c|c|c|}
\hline $\begin{array}{l}\text { Respiratory } \\
\text { phase }\end{array}$ & Inspiratory in nature & $\begin{array}{l}\text { Can be inspiratory or } \\
\text { inspiratory and expiratory }\end{array}$ \\
\hline Pitch & $\begin{array}{l}\text { Low-pitched, snoring type } \\
\text { sound }\end{array}$ & Variable pitch \\
\hline $\begin{array}{l}\text { Vocal } \\
\text { changes }\end{array}$ & No hoarseness of voice & Hoarseness of voice \\
\hline Position & Worse on supine position & Worse with exertion \\
\hline Cough & Cough and cry muffled & Cough harsh and barking \\
\hline
\end{tabular}




\section{Box 5 Pierre Robin sequence}

- Triad of micrognathia (small and symmetrically receded mandible), glossoptosis (tongue that obstructs the posterior pharyngeal space) and resultant airway obstruction first described in $1923 .{ }^{17}$

- Cleft palate occurs in up to $90 \%$. Main problems for children are airway obstruction and feeding difficulties.

- The prevailing concept is that mandibular hypoplasia leads to the sequence.

- Proposed mechanisms for the airway obstruction include the displacement of the tongue into the hypopharynx occluding the airway, disproportionate tongue growth causing prolapse into the cleft, lack of voluntary control of tongue musculature, and negative pull pressure of the tongue into the hypopharynx. ${ }^{17}$

- Abnormal maxillary morphology may cause mid- face hypoplasia.

- Airway obstruction improves with time as the mandible grows or because glossoptosis improves with growth and neurologic development. ${ }^{17}$

- $70 \%$ success rates have been quoted for non-surgical airway management.

- First approach is positioning prone.

- Tongue base airway obstruction can be relieved by nasopharyngeal airway (NPA). The use of the NPA has been used in hospital and home environments for weight gain and growth. ${ }^{18}$

referral was sent to the tertiary centre for specialist ENT opinion to find the root cause of the UAO.

By day 20, you feel you have done all the investigations that you can in a DGH (table 4). You have contacted a number of tertiary specialist teams to accept

\section{Box 6 Di George syndrome. ${ }^{19}$}

- The chromosome deletion of $22 q 11.2$ is involved in the majority of DiGeorge or velocardiofacial syndrome. There is wide phenotypic variability.

- Classical features are dysmorphic facies, conotruncal cardiac defects, hypocalcaemic hypoparathyroidism, T-cell-mediated immune deficiency and palate abnormalities.

- Learning, speech and feeding difficulties are seen, as are renal and musculoskeletal defects. Psychiatric disorders are increasingly being diagnosed.

- Can be autosomal dominant or arise de novo.

- The structures primarily affected are derivatives of the embryonic pharyngeal arches and pouches.

- Vascular rings have been described as an unusual association in this condition.
Table 4 Investigations completed by day 20

\begin{tabular}{|c|c|}
\hline Reviews and investigations & $\begin{array}{l}\text { Outcome and results of } \\
\text { investigations }\end{array}$ \\
\hline Echocardiogram & $\begin{array}{l}\text { Small patent foramen ovale, moderate } \\
\text { ventricular septal defect }\end{array}$ \\
\hline Chest X-ray & Normal lung fields, absent thymus \\
\hline Plastic team review & $\begin{array}{l}\text { No cleft palate } \\
\text { Mild Pierre Robin sequence }\end{array}$ \\
\hline Cranial ultrasound & Grade 1 intraventricular haemorrhage \\
\hline Electroencephalogram & No epileptiform activity \\
\hline $\begin{array}{l}\text { ENT review and nasopharyngeal } \\
\text { endoscopy }\end{array}$ & Large arytaenoids and bulky tongue \\
\hline Baseline blood investigations & $\begin{array}{l}\text { No evidence of sepsis: on empirical } \\
\text { intravenous antibiotics } \\
\text { hypocalcaemia: on treatment }\end{array}$ \\
\hline Genetics & Microarray results awaited \\
\hline Ophthalmology & No abnormalities detected \\
\hline Metabolic screen & Normal \\
\hline $\begin{array}{l}\text { Suspected gastro-oesophageal } \\
\text { reflux }\end{array}$ & Maximum antireflux treatment \\
\hline
\end{tabular}

ENT, ear nose and throat.

the patient including ENT, respiratory, as well as the DiGeorge team, but all have refused as the problem did not appear to be in their specialist area. Peter is stable, but CPAP-dependent with intermittent selfresolving desaturations, and therefore, does not need emergency admission. No tertiary team is willing to accept him for diagnostic work-up. The local ENT team has reached the limit of their investigative expertise, especially with such a small baby. So you, as the paediatrician, must make a diagnosis to get him in. From your perspective he is stuck!

On day 29, during your neonatal ward round, Peter is having significant bradycardias and desaturations dropping down to $60 \%$. Despite CPAP he is having $\mathrm{CO}_{2}$ retention and you decide to electively intubate and ventilate him. Now what?

Back to the drawing board. Peter is known to have biphasic stridor. Continuous positive pressure seemed to have kept his main airways open, and there is no concern about surfactant deficiency. Peter has got Di George syndrome. Could he have anything more than a VSD in the heart? Is it possible that he has an extrinsic airway compression; perhaps a vascular ring? Echocardiogram is what you easily have available, but it is not the investigation of choice for delineating the anatomy of vascular ring. Well, at least try and demonstrate a normal aortic arch and its branches.

You stabilise Peter on the ventilator and decide to do a detailed echocardiogram. The muscular VSD mentioned before is easily seen. There is a small flash of extra flow around the arch of aorta. But on which side is the aortic arch? Definitely left, no, definitely right. Hang-on, there are two aortic arches. 


\section{Box 7 Vascular rings and slings}

- Vascular rings are congenital vascular anomalies of the aortic arch complex which result in the compression of the trachea/oesophagus.

- They often manifest with airway compromise secondary to extrinsic tracheal compression. They can also present with feeding difficulty.

- Anatomically complete rings-double aortic arch, right aortic arch with aberrant left subclavian artery and left ligamentum, left arch with aberrant right subclavian artery and right ductus arteriosus. ${ }^{20}$

- Anatomically incomplete rings or vascular sling: innominate artery compression, aberrant right subclavian artery, pulmonary artery sling, aberrant left subclavian artery. ${ }^{20}$

- Investigations include chest X-ray, echo, CT scan, MRI, barium swallow and bronchoscopy. ${ }^{21}$

- Chest X-rays indirectly show the effect of the ring on adjacent structures: it can reveal laterality of the arch by contralateral deviation of the trachea. Double arch might be suspected with trachea compression at arch level. Lateral X-rays may also show tracheal compression, and airway radiographs can be useful in babies to reduced thymic interference.

- Echo can help determine laterality of the aortic arch and the branching pattern, but can be limited by poor acoustic windows, especially in ventilated patients. Relevant structures are often not visualised, and results are user dependent.

- Definitive investigations are cross-sectional imaging such as CT aortogram.

- Treatment is surgical.
Diagnosis: double aortic arch causing vascular ring? This is the limit of your expertise but you can now refer him to the cardiology team. Box 7 provides a revision of vascular rings and slings.

Peter is transferred to the tertiary centre under the cardiology team where a formal diagnosis of vascular ring is made. (table 5, figures 9 and 10). He undergoes patent ductus arteriosus (PDA) ligation and division to release the vascular ring. He has a prolonged stay due to the multiteam involvement for all his medical problems (table 5).

\section{Learning points}

- Tertiary hospitals should support secondary care, but with bed pressures and increasing specialism it can be difficult to get help.

- Don't be afraid to redo what was done before, or ask your colleagues to have a look.

- Not everyone has access to specialist investigations such as echo, consider tertiary review as a day case for a more complete scan.

\section{DISCUSSION}

UAO can be due to problems from the trachea, glottis and epiglottis, tonsils, vocal cords, and oesophagus or extrinsic compression of these structures. Evaluating these children is not easy as they need a multidisciplinary approach involving specialist investigations such as bronchoscopy, endoscopy, echocardiogram, MRI and so on. Interestingly, these specialist investigations are available in a DGH, but not for paediatricians.

Table 5 Final problem list and investigations

\begin{tabular}{|c|c|}
\hline Problems & Investigations and specialist reviews at the tertiary unit \\
\hline \multirow{3}{*}{$\begin{array}{l}\text { Final cardiac } \\
\text { diagnosis }\end{array}$} & Specialist echocardiogram \\
\hline & $\mathrm{CT}$ thorax to determine anatomy with three-dimensional reconstruction \\
\hline & $\begin{array}{l}\text { Vascular ring, double aortic arch with patent right arch, and atretic proximal left arch. Left PDA, left common carotid artery, left } \\
\text { subclavian artery, and left arterial duct supplied by a large patent left dorsal aorta, left superior vena cava to coronary sinus }\end{array}$ \\
\hline \multirow[t]{2}{*}{ ENT issues } & Vocal cord ultrasound-postoperative left vocal cord palsy \\
\hline & Microlaryngoscopy and bronchoscopy (MLB)_-bronchomalacia and mild laryngomalacia \\
\hline Hypocalcaemia & Endocrine review \\
\hline Stridor & Respiratory review \\
\hline Nasogastric feeding & Speech and language therapy (SALT) review-aspiration risk. \\
\hline \multirow[t]{2}{*}{ Poor feed tolerance } & Gastroenterology review for milk intolerance \\
\hline & Plan for impedance study \\
\hline 22q11 deletion & Seen by genetics and DiGeorge team \\
\hline
\end{tabular}

ENT, ear nose and throat; PDA, patent ductus arteriosus. 


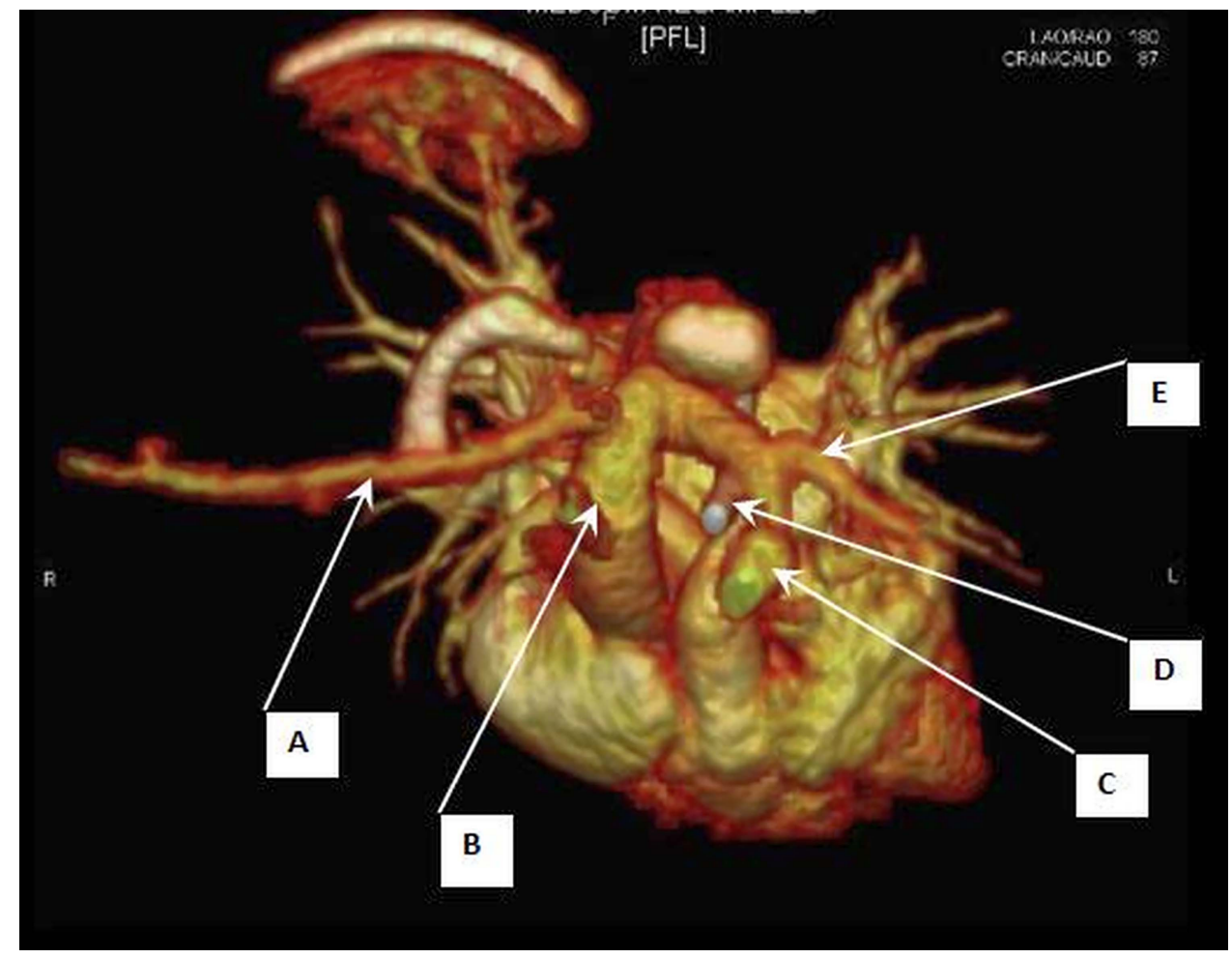

Figure 9 Anterosuperior CT image of double aortic arch and vasculature. (A) Right subclavian artery. (B) Dominant right aortic arch. (C) Left common carotid artery from left aortic arch. (D) Ductal remnant. (E) Left subclavian artery from left aortic arch.

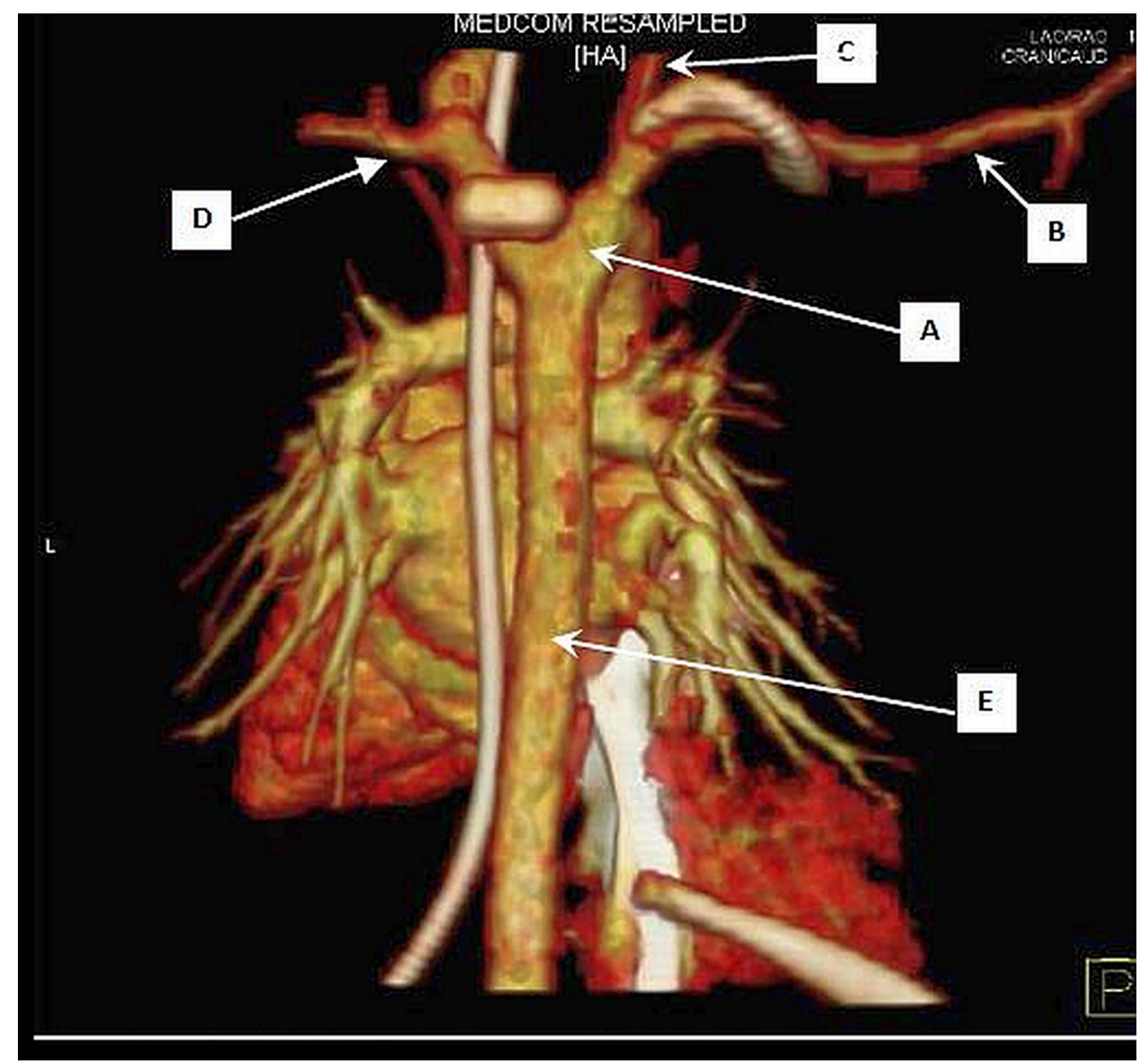

Figure 10 Posterior CT image of double aortic arch. A: Dominant right aortic arch giving rise to right subclavian arteries (B) and right common carotid arteries (C). D: Left aortic arch with left common carotid and left subclavian arteries. E: Descending aorta. 
This is because of age constraints, lack of expertise, and centralisation of paediatric specialist services; albeit for good reasons.

Getting these children accepted by tertiary specialist hospitals is not easy. Tertiary clinicians are subspecialty based, and accept children only if the problem comes under their own subspecialty. Causes of UAO can fall into number of subspecialties including ENT, respiratory and cardiology, so it is easy for specialist teams to attribute the cause to a different speciality. The paediatrician, therefore, is forced to fall back to careful history taking, examination and careful assessment of routine investigations like radiographs, infection parameters and so on, for clues for the final diagnosis. Table 6 gives a pattern of clinical features at different levels of UAO.

It is important not to forget subtle clues given by the nursing staff. With Sophie, the nurses mentioned in a conversation 'You know, Sophie would not go to sleep. It's as if she knows that she will have apnoea if she sleeps'.

With the decreased incidence of acute epiglottitis, following the implementation of haemophilus influenza type $B$ vaccination, it is easy to underestimate and forget the degree of difficulty in intubating and stabilising children with UAO. ${ }^{23}$ As is well known, these procedures should be undertaken by a multidisciplinary team including an ENT surgeon in theatres with a tracheostomy set ready. Invasive procedures such as flexible laryngoscopy or even intravenous line insertion can precipitate fatal airway obstruction. Children, even those with the most severe UAO, surprisingly maintain their airway when awake to such an extent that clinicians can underestimate the severity of the obstruction. The picture of Sophie in a pram, quite alert looking at the consultants discussing the strategies of intubating and stabilising her, is still vivid in our memories. As noted above, she had one of the most difficult intubations we have seen.

Table 6 Clinical signs and symptoms typical of upper airway obstruction at different anatomical levels

\begin{tabular}{ll}
\hline Location & Typical signs and symptoms \\
\hline Pharynx & $\begin{array}{l}\text { Hot potato voice, drooling, odynophagia } \\
\text { (painful swallowing), stertor, worse on } \\
\text { supine position } \\
\text { Hot potato voice, drooling, odynophagia, } \\
\text { inspiratory stridor }\end{array}$ \\
Gupraglottis & $\begin{array}{l}\text { Hoarse or raspy voice, normal swallowing, } \\
\text { barking cough, inspiratory or biphasic stridor }\end{array}$ \\
$\begin{array}{l}\text { Tracheobronchial tree } \\
\text { (intrathoracic) }\end{array}$ & $\begin{array}{l}\text { Normal voice, normal swallowing, expiratory } \\
\text { stridor, wheeze, etc }\end{array}$ \\
\hline
\end{tabular}

Adapted from Pediatric ENT. 2007 With kind permission of Springer Science+Business Media. ${ }^{22}$

ENT, ear nose and throat.

\section{CONCLUSION}

In most of the cases of UAO, the aetiology is fairly obvious. However, difficult cases as mentioned above, though uncommon, still present to the DGH. It is imperative that the DGH paediatrician gives importance to aetiological management rather than symptomatic management. If the aetiology is not clear, it is important to start from scratch rather than continuing the same treatment path followed before. Attention to detail using basic old-fashioned clinical medicine will give hints towards the final diagnosis. However, at this juncture, the DGH paediatrician needs all the support he can get from his adult speciality colleagues and tertiary specialists. It is important that tertiary specialist clinicians work as a team, across their expertise, to address the presenting problem of a child, depending on the severity and what is available in DGH.

With the current trend of increasing centralisation of paediatric specialist services in the UK, it is crucial that there is seamless communication and clinical networking between secondary and tertiary services for specialist advice, investigations and treatment. Specialist children's retrieval teams play a vital role as a bridge between these interfaces, in particular for children who need intensive care and high dependency care. The same enthusiasm shown to centralise paediatric specialist care should be shown to address the chronic shortage of beds in tertiary hospitals.

Acknowledgements The authors would like to extend their gratitude to the children and their families for their understanding and encouragement to publish and learn from their experiences. All images obtained from Broomfield Hospital and Great Ormond Street Hospital with kind permission from Dr G Derrick, Dr C Owens, and Dr P De Coppi. Thanks to Dr Anthony Lipscomb for advice and revision of the article and Mr Lijo Thomas and Ms Joyce Salazar for editing pictures.

Contributors $\mathrm{KH}$ formulated the first draft of the article, revised the article appropriately and was responsible for acquisition of some of the investigations. All cases described in the article were managed by JC and his clinical team. JC is responsible for the conception and design of the article, obtained investigations, obtained consents, and finalised the article.

Competing interests None.

Patient consents Obtained.

Provenance and peer review Not commissioned; internally peer reviewed.

\section{REFERENCES}

1 William DG, Jaggar SI, Morgan CJ. Upper airway obstruction as a result of massive surgical emphysema following accidental removal of an intercostal drain. Br J Anaesth 2005; 94:390-2.

2 Schumann R, Polaner DM. Massive subcutaneous emphysema and sudden airway compromise after postoperative vomiting. Anaesth Analg 1999;89:796-7966. 
3 Gibney RT, Finnegan B, Fitzgerald MX, et al. Upper airway obstruction caused by massive surgical emphysema. Intensive Care Med 1984;10:43-4.

4 Reilly J, Thompson J, MacArthur C, et al. Paediatric aerodigestive foreign body injuries are complications related to timeliness of diagnosis. Laryngoscope 1997;107:17-20.

5 Kay M, Wyllie R. Paediatric Foreign Bodies and their management. Curr Gastroenterol Rep 2005;7:212-18.

6 Arthur R. Interpretation of the paediatric chest x-ray. Current Paediatrics 2003;13:438-47.

7 Johnsons C, Goodman NW. Time to stop sniffing the air: snapshot survey. BMJ 2006;333:1295-6.

8 Kakani S. Airway compromise in infectious mononucleosis: a case report. Cases J 2009;2:6736.

9 Simcock A, Prout B. A patient with respiratory obstruction in glandular fever. Thorax 1974;29:145-6.

10 Jenson HB. Acute complications of Epstein-Barr virus infectious mononucleosis. Curr Opin Pediatr 2000;12:263-8.

11 Candy B, Hoptof M. Steroids for symptom control in infectious mononucleosis. Cochrane Database Syst Rev 2006;19:CD004402.

12 http://emedicine.medscape.com/article/995851-overview

13 Craig FW, Schunk JE. Retropharyngeal abscess in children; Clinical presentation, Utility of Imaging and Current Management. Pediatrics 2003;111:1394-8.

14 Rotta AT, Wiryawan B. Respiratory emergencies in children. Respir Care 2003;24:248-58.
15 Lalakea MI, Messner AH. Retropharyngeal abscess management in children: current practices. Otolaryngol Head Neck Surg 1999;121:398-405.

16 Graber MA, Kathol M. Cervical spine radiographs in the trauma patient. Am Fam Physician 1999;59:331-42.

17 Evans KN, Sie KC, Hopper RA, et al. Robin sequence: from diagnosis to development of an effective management plan. Pediatrics 2011;127:936-48.

18 Abel F, Bajaj Y, Wyatt M. The successful use of nasopharyngeal airway in Pierre Robin Sequence: an 11 year experience. Arch Dis Child 2012;97:331-4.

19 Cuneo BF. 22q11.2 deletion syndrome: DiGeorge, velocardiofacial, and conotruncal anomaly face syndromes. Curr Opin Pediatr 2001;13:465-72.

20 Shah RK, Mora BN, Bacha E, et al. The presentation and management of vascular rings: an otolaryngology perspective. Int J Pediatr Otorhinolaryngol 2007;71:57-62.

21 Woods RK, Sharp RJ, Holcomb GW, et al. Vascular Anomalies and tracheoesophageal compression: a single institution's 25 year experience. Ann Thoracic Surg 2001;72:434-8.

22 Graham JM, Scadding GK, Bull PD. Pediatric ENT. Springer, 2007:P185.

23 Immunisation against infectious disease: the green book. Public health England. https://www.gov.uk/government/publications/ haemophilus-influenzae-type-hib-the-green-book-chapter-16 ns/ haemophilus-influenzae-type-hib-the-green-book-chapter-16/ Published 11 September 2013. (accessed 8 Nov 2013). 